\title{
AS POLÍTICAS DE AÇÕES AFIRMATIVAS PARA A CONCRETIZAÇÃO DE DIREITOS AOS GRUPOS SOCIAIS NEGROS NO BRASIL
}

\author{
Danielle Annoni \\ Fernanda da Silva Lima
}

\section{RESUMO}

Este trabalho ressalta a importância do investimento em políticas de ações afirmativas para a concretização dos direitos dos grupos sociais negros no país e para a promoção da igualdade racial na sociedade. Neste sentido, visou-se destacar a construção histórica e social das relações raciais no Brasil e os reflexos das políticas de ações afirmativas na efetivação dos direitos de cidadania das minorias.

Palavras-Chave: Ações afirmativas. Igualdade racial. Minoria Negra.

\section{INTRODUÇÃO}

Como premissa introdutória é importante ressaltar a importância do investimento em políticas públicas de ações afirmativas para a concretização dos direitos dos grupos sociais negros no país para que seja possível alcançar o equilíbrio e a promoção do ideal de igualdade racial na sociedade.

Este ensaio procura demonstrar a imprescindibilidade das ações afirmativas na luta anti-racista e para isso é necessário um breve resgate histórico de como são as relações raciais na atual sociedade brasileira. A luta anti-racista remonta desde 0 período escravocrata e segue ainda no período pós-abolição, uma vez que os grupos sociais negros ainda vivem à margem da sociedade.

O trabalho traz uma abordagem sócio-jurídica de como são as relações raciais no Brasil para que seja possível compreender o porquê da necessidade de ações afirmativas voltadas para a população negra. Trabalha com os fenômenos do preconceito racial, do racismo e da discriminação racial como condicionantes da desmistificação da falsa democracia racial construída no país nas primeiras décadas do século XX. Reafirma a importância do movimento negro na sua trajetória histórica e na luta anti-racista. Além de tentar dar uma dimensão social e exemplificar a admissibilidade das ações afirmativas como condicionantes de transformação humana e concretizadora dos direitos dos grupos sociais negros.

\section{A luta anti-racista no Brasil: uma breve incursão histórica.}

É inegável que a atual sociedade brasileira ainda esteja impregnada pelos fenômenos do racismo, do preconceito racial e da discriminação racial ${ }^{3}$ sofrida pelos grupos sociais negros. A luta anti-racista no Brasil foi arquitetada ainda durante o regime de escravidão por grupos contrários a esse modelo econômico e político que teve vigência plena por mais de três séculos. Passados 121 anos da abolição legal 
da escravidão ainda é possível perceber que o negro permanece desintegrado socialmente.

A abolição da escravatura não livrou o negro da sua condição de espoliação, simplesmente porque para as novas visões do mercado, da sociedade e da política, ele tornou-se descartável. Não houve investimento em políticas inclusivas para que os negros se integrassem a essa nova sociedade, simplesmente porque a abolição não foi para eles. A abolição não alterou em nada a situação dos negros, eles continuaram carregados de estereótipos - seres inferiores, vadios, preguiçosos, ociosos -, assim como a abolição '[...] não trouxe consigo a perspectiva de libertação com plena inserção dos descendentes de negros escravizados na sociedade como um todo, isto é, no mercado de trabalho, no sistema educacional, no acesso à moradia digna, à posse da terra, entre outras',

FERNANDES afirma que após a abolição "o negro permaneceu sempre condenado a um mundo que não se organizou para tratá-lo como ser humano e como igual"." A historiografia brasileira aponta que a omissão do Estado perante os grupos sociais negros foi proposital, não houve qualquer investimento de integração dos negros nessa nova sociedade que emergiu no final do século XIX. Ao contrário, o que se vislumbrou foi um duplo processo de exclusão, o primeiro em decorrência de uma abolição incompleta e o segundo em razão do investimento público na imigração.

O fluxo imigracional foi intensificado no período entre 1884 e 1913, tendo ingressado no Brasil cerca de 2,7 milhões de europeus. Apenas a título de comparação, nesses 29 anos, a quantidade de imigrantes que ingressou no Brasil, incentivada por uma política imigratória, representou $70 \%$ do total de africanos que ingressaram na condição de escravos durante os mais de três séculos de escravidão. Esses números refletem o projeto de "branqueamento" que se visou desenvolver no país, na tentativa de eliminar os grupos sociais negros e indígenas, uma vez que sua presença refletia o passado escravista e suas mazelas. Neste sentido, o objetivo da elite escravocrata desse período foi se redimir em face das nações européias, eliminado o negro do contexto social, ou seja, transformando o Brasil em uma "nação ocidental e branca". 6

Atualmente o ideário de branqueamento serve como suporte ideológico para mascarar a discriminação racial na sociedade. Serve como instrumental de anulação e negação das demais culturas e das demais cores, em detrimento da cultura ocidental e branca. $O$ próprio negro atualmente na sociedade não se sente negro, há uma perda de identidade, justamente porque até hoje não se conseguiu romper com esse círculo vicioso de inferioridade que permeia as "pessoas de cor".

O discurso da mestiçagem e da democracia racial que surgiu no Brasil no início do século $X X$, principalmente após a edição das obras de Gilberto Freyre ${ }^{7}$ contribuíram para fomentar a ideologia de um país sem preconceito ou discriminação fundada na "cor", já que o fato de o povo brasileiro ser, por origem, essencialmente mestiço, composto basicamente da mistura entre brancos, negros e indígenas, bastaria para afastar qualquer processo, ação ou intenção de exclusão social em forma de discriminação ou racismo. 
Afirmar a mestiçagem implicou, durante anos, no não reconhecimento das diversas minorias, porque se essas já estavam integradas, não se consistiam, em verdade, em minorias, logo, precisavam de tratamento diferenciado, protetivo ou de inclusão. Ao contrário, pensar em criar ações específicas em prol de determinados grupos sociais correspondia a fomentar a discriminação e a desigualdade, já que todos, no Brasil, eram, segundo a ideologia dominante, iguais por origem histórica, pela cultura mestiça e pela diversidade de identidades.

A influência das obras de Freyre é ainda sentida no meio acadêmico nacional. CHAUí afirma que "a sociedade mestiça desconhece o preconceito racial"." 0 discurso da mestiçagem serviu, como dito, como elemento ideológico que embasou - mito da democracia racial e consequentemente a negação do racismo escamoteado nas práticas sociais.

De acordo com GUIMARÃES ${ }^{9}$, o mito da democracia racial aparece como subterfúgio para explicar no Brasil uma inexistência de minorias étnicas, e o emprego da mestiçagem como sinônimo de harmonia social entre os diversos grupos étnicos brasileiros. Historicamente a utilização do termo "raça" - para definir a existência dos diversos grupos étnicos do país - foi uma proposta que partiu dos próprios movimentos negros como mecanismo de denúncia da falsa mestiçagem brasileira e do mito da democracia racial.

A Frente Negra Brasileira ${ }^{10}$, movimento social que se converteu em partido político em 1936 já compreendia a necessidade de revalorização do termo "raça" no que tangia a identidade étnica como manifestação de uma luta anti-racista e pelo reconhecimento da situação marginal dos negros no Brasil.

Entre os anos de 1940 e 1960 outros movimentos sociais começavam a surgir no cenário político brasileiro, entre eles a União dos Homens de Cor e o Teatro Experimental do Negro, liderado por Abdias do Nascimento no Rio de Janeiro entre os anos de 1944-1964. A retomada dos movimentos sociais a partir da década de 1970, ainda durante o regime militar no Brasil, permitiu que as lideranças negras se reorganizassem politicamente e rediscutissem novas bases para uma luta antiracista no país. ${ }^{11}$ A criação do Movimento Negro Unificado (MNU) em 1978 '[...] pôs na ordem do dia as desigualdades $e$ as discriminações raciais vigentes no Brasil $[. .]^{\text {,12 }}$, denunciando-as para o resto do mundo, tendo em vista a visibilidade internacional que conquistou o MNU.

Na pauta de luta do Movimento Negro Unificado estava realmente implícita o desejo de transformar a sociedade brasileira numa verdadeira democracia racial. Essa militância teve como principais objetivos denunciar que as desigualdades sociais entre negros e brancos no Brasil não eram apenas o reflexo da disputa de classes $^{13}$, mas por em evidência o preconceito e a discriminação racial, como fatores determinantes da situação marginal da minoria negra.

O processo de mobilização e luta por melhores condições de vida à população negra deveria guiar-se pela "segunda abolição", nas palavras de FERNANDES ${ }^{14}$, e ser implementada pelos próprios negros como alternativa para melhorar a sua condição de vida e a sua condição social. 
A partir dos anos 1980 intensificou-se no país a luta dos vários movimentos sociais, incluindo os movimentos negros, que reivindicavam entre suas lutas particulares a redemocratização ${ }^{15}$ brasileira e a promulgação de uma Constituição de base democrática.

Os trabalhos da Assembléia Nacional Conseguinte no ano de 1987 foram realizados mediante a participação da sociedade civil organizada. Os movimentos negros colocaram em pauta as suas principais reivindicações, dentre as quais podese destacar: a) denunciar o racismo e a discriminação racial pelo qual sofrem as minorias negras brasileiras; b) denunciar a democracia racial como mito e forma de impedir o investimento em políticas públicas de ações afirmativas na luta anti-racista; c) resgatar a cultura afro-brasileira por meio do reconhecimento das diversas identidades, da valorização da diversidade e do reconhecimento de uma sociedade multirracial e multicultural. ${ }^{16}$

A Constituição da República Federativa do Brasil promulgada em 05 de outubro de 1988 assegurou a volta da democratização ao país e inaugurou um novo momento na história do Direito, tendo no princípio da Dignidade da Pessoa Humana seu marco, além de fazer prevalecer o interesse da coletividade sobre o interesse individual. A Constituição Federal de 1988 assegurou a igualdade de todos perante a lei, não apenas no aspecto formal, mas sim e principalmente, em seu aspecto material, devendo ao Estado e seus representantes assegurarem tal garantia em todos os âmbitos da vida em sociedade. Ademais, conferiu ao Supremo Tribunal Federal o status de Corte Constitucional Brasileira, cabendo a esse poder garantir a eficácia dos princípios constitucionais.

Dentre os artigos da Constituição Federal de 1988 que versam sobre o tema, merecem destaque:

Art. $3^{\circ}$. Constituem objetivos fundamentais da República Federativa do Brasil:

I - construir uma sociedade livre, justa e solidária;

II - garantir o desenvolvimento nacional;

III - erradicar a pobreza e marginalização e reduzir as desigualdades sociais e regionais;

IV - promover o bem de todos, sem preconceitos de origem, raça, sexo, cor, idade e quaisquer outras formas de discriminação. (grifo nosso).

Conforme se depreende do artigo citado é dever do Estado assegurar os direitos e garantias individuais e igualitárias a todas as pessoas sem distinção. É vedado qualquer manifestação discriminatória ou racista fundada na cor da pele e na raça. Essa foi uma conquista importante dos movimentos negros, eis que denunciaram as discrepâncias sociais existentes entre os diversos grupos sociais que compõem a sociedade brasileira.

O próximo artigo refere-se às garantias individuais inerentes a pessoa humana, consagrando a igualdade a todas as pessoas, conforme a redação do caput do art. $5^{\circ}$ : 
Art. $5^{\circ}$ Todos são iguais perante a lei, sem distinção de qualquer natureza, garantindo-se aos brasileiros e aos estrangeiros residentes no País a inviolabilidade do direito à vida, à liberdade, à igualdade, à segurança e à propriedade [...]. (grifo nosso).

Cabe reforçar que numa sociedade desigual como a nossa, a igualdade que se pretende alcançar é a igualdade material e não meramente formal. Numa sociedade pluriétnica e multicultural o Direito tem 0 dever de amparar as adversidades jurídicas e contribuir para a resolução efetiva das distorções sociais existentes.

O censo realizado pelo Instituto Brasileiro de Geografia e Estatística (IBGE) do ano de 2000 revelou que a população negra ${ }^{17}$ representa mais de $45 \%$ da população brasileira. Da população brasileira que vive na linha da pobreza, as minorias negras correspondem a $65 \%$, e, da população brasileira que vive em extrema pobreza, na mais plena miséria, a comunidade negra corresponde a $70 \%$. Em contrapartida, a população branca brasileira, embora corresponda a mais de $54 \%$ da população nacional, apenas $35 \%$ são pobres e menos de $30 \%$ podem ser enquadrados abaixo da linha de pobreza. ${ }^{18}$

Os indicadores sociais publicados pelo Instituto Brasileiro de Geografia e Estatística, no ano de 2008, com base nas informações prestadas pela Pesquisa Nacional por Amostra de Domicílios (PNAD), obtidos durante o ano de 2007 e que possui cobertura em todo território nacional, aponta que as desigualdades sociais entre os grupos sociais brancos e negros levando em consideração a renda per capita das famílias só aumentaram em comparação a pesquisas realizadas anteriores por este mesmo instituto ${ }^{19}$.

O gráfico abaixo mostra a distribuição do rendimento familiar per capita das pessoas de 10 anos ou mais de idade, com rendimento, entre os $10 \%$ mais pobres e o 1\% mais rico, em relação ao total de pessoas, fazendo um recorte racial no Brasil. Os dados sugerem que no ano de 2007 entre os $10 \%$ mais pobres os negros correspondiam a $73,9 \%$ da população, enquanto que os brancos $25,5 \%$. Em relação ao $1 \%$ mais rico os negros correspondem a $12 \%$ enquanto que a população branca o índice é de $86,3 \% .^{20}$ 


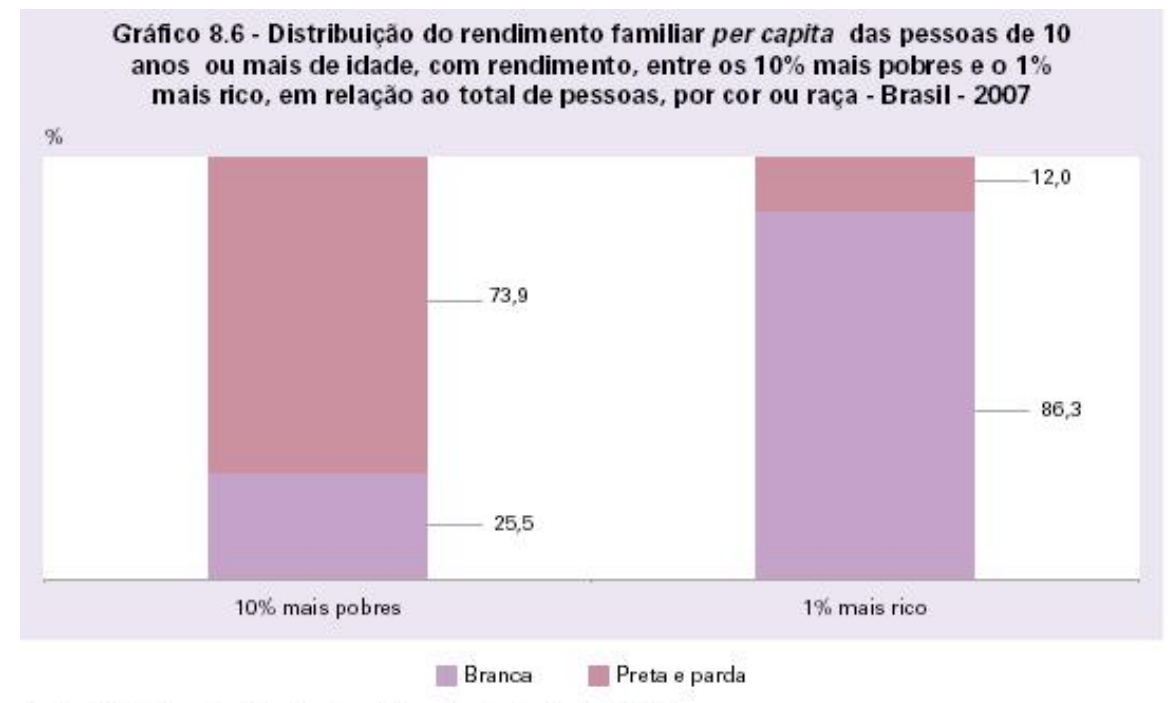

Fonte: IBGE, Pesquisa Nacional por Amostra de Domicilios 2007

A pesquisa também aponta que no ano de 2007 havia cerca de 14 milhões de analfabetos brasileiros e que desses, quase 9 milhões correspondiam a população de pretos e pardos, o que comprova que para os grupos sociais negros essa situação continua extremamente grave. 'Em termos relativos, a taxa de analfabetismo da população branca é de 6,1\% para as pessoas de 15 anos ou mais de idade, sendo que estas mesmas taxas para pretos e pardos superam $14 \%$, ou seja, mais que o dobro que a de brancos., ${ }^{, 21}$

[...] o analfabetismo é um fator de marginalização, que exclui e impede a mobilidade social da criança, do jovem, do homem e da mulher. As elevadas taxas de analfabetismo que ainda subsistem em diversas áreas é um indicador de exclusão de expressivas camadas da população mundial e refletem as dificuldades enfrentadas pelos governos para erradicação deste sério problema. ${ }^{22}$

Em relação às pesquisas anteriores desenvolvidas pela PNAD é possível concluir que a média de anos de estudo da população com 15 anos ou mais de idade continua a apresentar uma vantagem em torno de 2 anos para a população branca que apresenta 8,1 anos de estudos enquanto que a população negra é de 6,3 anos, conforme o gráfico que segue: 
Gráfico 8.3 - Média de anos de estudo das pessoas de 15 anos ou mais de idade, por cor ou raça, segundo as Grandes Regiões - 2007

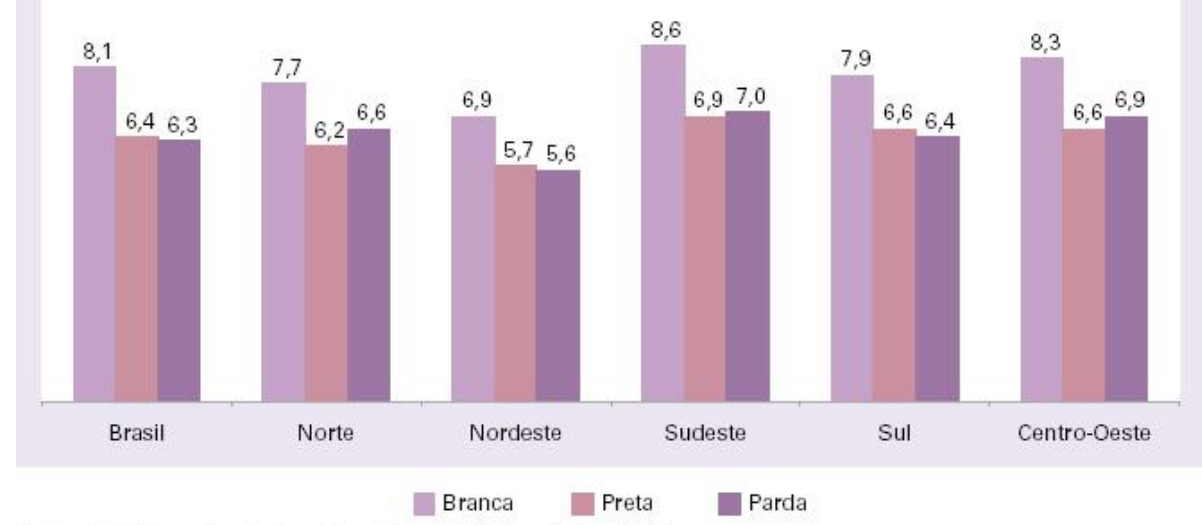

Fonte: IBGE, Pesquisa Nacional por Amostra de Domicilios 2007

De acordo com os indicadores sociais constantes na pesquisa realizada pelo PNAD pode-se constatar que a diferença de escolaridade entre os grupos brancos e negros é acentuada acarretando inúmeros prejuízos para o segundo, principalmente no que se refere ao acesso e a permanência ao ensino superior, mercado de trabalho e rendimentos salariais.

Esses números revelam o quão desigual vivem os grupos sociais brancos e negros no Brasil, e como esta desigualdade fomenta o ciclo vicioso da pobreza. Nesse sentido, somente um sério investimento em políticas de ações afirmativas nas mais diversas áreas poderá reverter esse ciclo, oportunizando a minoria negra construir um futuro mais digno igual para seus descendentes.

\section{As políticas de ações afirmativas no Brasil: breves considerações}

É difícil datar precisamente o aparecimento de políticas de ação afirmativa implementadas por algumas nações. GUIMARÃES indica que a primeira referência ao termo ação afirmativa apareceu em uma legislação trabalhista britânica no ano de 1935 (The 1935 National Relations Act). Conforme essa legislação qualquer empregador que discriminasse um operário seria sancionado e tanto o empregador quanto aos sindicalistas deveriam, mediante ações afirmativas, realocar a pessoa discriminada ao trabalho, levando-se em consideração ainda o cargo ou função que essa pessoa ocuparia se não tivesse sido alvo da discriminação. ${ }^{23} \mathrm{~A}$ ação afirmativa, nesse sentido, tinha a função de reparação por uma injustiça sofrida.

No entanto a utilização do termo ação afirmativa (affirmative action), empregada na sua forma literal tal como se conhece atualmente foi utilizada pela primeira vez nos Estados Unidos no ano de 1961 sob o governo do presidente John F. Kennedy, tendo como finalidade a ampliação de oportunidades no ensino e no mercado de trabalho, como alternativa de alcançar a equidade social entre negros e brancos.

As ações afirmativas nos Estados Unidos foram alcançadas mediante um processo de mobilização social e lutas por direitos civis. ${ }^{24} \mathrm{E}$, por isso 0 
reconhecimento de que foram os Estados Unidos o primeiro Estado a tentar coibir qualquer forma de segregação racial, evidenciando principalmente o preconceito, 0 racismo e a discriminação racial que sofriam os grupos sociais negros naquele país.

As tentativas iniciais de combater a segregação racial nos Estados Unidos e assegurar 0 acesso igualitário entre negros e brancos, ao ensino e ao mercado de trabalho não surtiram os efeitos pretendidos, em regra, pela negativa da população branca em implementá-las, não logrando êxito em reverter o quadro das distorções raciais vivenciadas naquele período.

Todavia, no início da década de 1970, diante da ineficácia de implementação das ações afirmativas houve uma mudança no aspecto conceitual de tais políticas, e foi somente durante a administração de Kennedy e Johnson que as ações afirmativas ganharam maior alcance e visibilidade. A prática das ações afirmativas foi garantida por meio do que se convencionou chamar de "cotas rígidas", ou metas (goals) que as empresas e as instituições de ensino deveriam alcançar para assegurar 0 acesso ao emprego e ao ensino para determinadas categorias marginalizadas, englobadas numa perspectiva de raça, gênero, etnia, nacionalidade, dentre outras minorias.

As ações afirmativas implementadas nos Estados Unidos dividiram a opinião pública e até mesmo a comunidade acadêmica, tornando-se um tema polêmico e em constante debate. Os críticos as ações afirmativas, negam sua eficácia, enquanto que os que as apóiam ressaltam suas conquistas e entendem que a consolidação de uma classe média negra naquele país é conseqüência legítima do investimento nessas políticas. ${ }^{25}$ Para ALMEIDA

[...] de uma maneira geral, os efeitos práticos dos programas de ação afirmativa nos Estados Unidos, após trinta anos, são positivos, visto que, possibilitaram a promoção de direitos sociais, econômicos, educacionais e culturais para negros e outros grupos minoritários. Trata-se, portanto, de uma prática duradoura que pode servir de referência para criarmos nosso próprio modelo. ${ }^{26}$

Isso não implica dizer que o Brasil deve importar o modelo estaduniense integralmente. Cada Estado possui suas peculiaridades e, nesse sentido, as ações afirmativas brasileiras devem respeitar as diversas características nacionais.

O ex-presidente Fernando Henrique Cardoso ao abrir o Seminário Multiculturalismo e Racismo: o papel da Ação Afirmativa nos Estados Democráticos Contemporâneos, ocorrido em Brasília no ano de 1996, pronunciou-se no sentido de que no Brasil essas políticas precisam atender as verdadeiras necessidades do país, não bastando, simplesmente importar formas de implementação dessas políticas como ocorrem em outros lugares no mundo. De acordo com o ex-presidente é necessário

[...] ter criatividade, temos de ver de que maneira a nossa ambigüidade, essas características não cartesianas do Brasil - que dificultam tanto em tantos aspectos -, também pode ajudar em outros aspectos. Devemos, pois buscar soluções que não sejam pura e simplesmente repetição ou a cópia de soluções imaginadas para situações em que também há discriminação e 
preconceito, mas em um contexto diferente do nosso. É melhor, portanto, buscarmos uma solução mais imaginativa. ${ }^{27}$

Atualmente o termo ações afirmativas precisa ser redefinido conceitualmente. É imprescindível que se rompa com a velha concepção de reparação por uma injustiça histórica que permeia o conceito das ações afirmativas. Para GUIMARÃES "a noção moderna se refere a um programa de políticas ordenado pelo executivo ou pelo legislativo, ou implementado por empresas privadas, para garantir a ascensão de minorias étnicas, raciais e sexuais". ${ }^{28}$

Essas políticas devem ser invocadas pelo Estado sempre que haja a necessidade de sua implementação, independentemente das concessões necessárias a sua efetivação. A construção de um sociedade democrática e igualitária implica em concessões mutuas e recíprocas por parte de todos que a compõem. A expectativa de reparação deve ser substituída pela da concessão de direitos aos grupos socialmente desprivilegiados e discriminados. Diante dessa situação as ações afirmativas se materializam como instrumentos concretos de efetivação dos direitos fundamentais, sobretudo do direito à igualdade material. GOMES:

A essa concepção soma-se o conceito de ações afirmativas definido por As ações afimativas se definem como políticas públicas (e privadas)
voltadas à concretização do princípio constitucional da igualdade material e
à neutralização dos efeitos da discriminação racial, de gênero, de idade, de
origem nacional e de compleição física. Na sua compreensão, a igualdade
deixa de ser simplesmente um princípio jurídico a ser respeitado por todos,
e passa a ser um objetivo constitucional a ser alcançado pelo Estado e pela
sociedade.

Assim, as ações afirmativas devem ser resultado de um conjunto de políticas públicas que verdadeiramente contribuam para a eliminação de quaisquer tipos de discriminação - seja racial, de gênero, de compleição física e outros -, uma vez que a história nacional demonstra que não basta a edição de normas proibitivas de condutas discriminatórias, é necessário criar mecanismos de emancipação humana do sujeito discriminado, para que ele deixe de ocupar uma posição de inferioridade ou de desprestígio social, e, alcançando status diferenciado, tenha condições de fomentar mudanças no seu ciclo familiar, contribuindo assim para romper o circulo da pobreza e da exclusão.

Em relação aos grupos sociais negros, o investimento em políticas de ações afirmativas pode também contribuir como um mecanismo de combate à discriminação racial, pois a medida em que essa minoria for ocupando espaços de prestígio social na comunidade, gradativamente irá se desfazer a "imagem social" de que a pessoa negra no Brasil não é capaz. Esse estereótipo é alimentado pela ausência de condições por parte da comunidade negra de atingir o nível superior de educação no Brasil, sendo sempre vista em funções e cargos de nível elementar ou, mesmo quando atingem status social relevante, raramente tal status corresponde a espaços de poder intelectual. 
Mas a questão não é tão simples. VIEIRA aponta que os estudos sobre ações afirmativas em sua grande maioria ficam reduzidos ao desenvolvimento de quatro pontos específicos, quais sejam:

1) analisam os reflexos do modelo norte-americano, mais especificamente das políticas de cotas; 2) consideram o caráter histórico e a constituição do preconceito no Brasil, e as possibilidades de ação afimativa nesse contexto; 3) formulam análises legais sobre sua aplicabilidade, ou 4) finalmente, analisam os programas já existentes. ${ }^{30}$

Em relação ao primeiro, faz-se imperioso o conhecimento de como as ações afirmativas foram implementadas em outros Estados, mais especificamente nos Estados Unidos pela sua trajetória histórica, assim como pelo sucesso que a aplicação dessas medidas proporcionou a população estaduniense. No entanto, é preciso ressaltar, quando se analisa o direito comparado, que cada Estado tem suas peculiaridades próprias. As ações afirmativas, como já mencionado, devem ser o resultado do conjunto de políticas públicas para oportunizar igualdade de condições, acesso e permanência, em ambientes como: ensino, mercado de trabalho, saúde, lazer, cultura, etc., e que não necessariamente perpassa apenas por uma política de cotas.

A política de cotas destinada à garantia de acesso ao ensino superior a estudantes que economicamente ocupam posição desprivilegiada ou a grupos socialmente discriminados e marginalizados, como é o caso no Brasil dos negros e dos índios, cabe frisar, representam apenas uma modalidade de política inclusiva inserido num programa maior - as ações afirmativas. Não se pode reduzir uma política de ação afirmativa a mera aplicação de cotas universitárias, pois as cotas compõem apenas uma das medidas possíveis dentro do campo de atuação das ações afirmativas.

O segundo tópico trazido pela autora demonstra a necessidade de fundamentar o "por quê?" das ações afirmativas. E para isso é necessário um aporte teórico de como as discriminações ocorrem na sociedade brasileira, assim como é fundamental o estudo numa perspectiva histórica.

No terceiro item os estudos estão mais focalizados em compreender a implementação das ações afirmativas sob a ótica do Direito. Se essas políticas são constitucionais ou não, se as normas atualmente vigentes dão conta de aplicar em termos práticos essas medidas. Enfim, pretende-se verificar se as ações afirmativas são passíveis de existirem no campo da eficácia e validade jurídica.

E no último item apontado pela autora, os estudos em ações afirmativas têm uma preocupação em analisar os programas atualmente existentes, como se comportam e se os mesmos são aceitos socialmente. Estudam os grupos privilegiados diretamente por essas medidas inclusivas, analisam a eficácia e evolução dos programas e por fim, propõem alternativas e novas soluções que contribuam para a melhoria no campo de atuação dos programas que implementam ações afirmativas.

As políticas de ação afirmativa têm características próprias, devem ser implementadas temporariamente e devem ser focalizadas, ou seja, a sua 
implementação deve estar condicionada a um prazo de aplicação, bem como a completa definição de quais serão os grupos acolhidos por essas políticas. Além disso, as ações afirmativas têm a finalidade de oportunizar igualdade de condições a grupos socialmente discriminados, ou que não consigam sem a interferência direta das ações afirmativas se igualar materialmente aos demais grupos, independentemente de qual seja o âmbito de atuação dessas medidas: seja o educacional, o mercado de trabalho, a cultura, ao esporte, a habitação, etc. ${ }^{31}$

A pesquisa sobre a desigualdade racial no Brasil desenvolvida pelo Instituto de Pesquisas Econômicas e Aplicadas (IPEA) no ano de 2002 sob a coordenação de Lucina Jaccoud e Nathalie Beghin aponta que:

\begin{abstract}
O surgimento de propostas de ação afimativa assenta-se em uma crítica ao ideal de igualdade de direitos como instrumento eficaz para a promoção da igualdade. $O$ reconhecimento de que a igualdade formal não garante aos que são socialmente desfavorecidos o acesso às mesmas oportunidades que têm aqueles que são socialmente privilegiados promoveu um esforço de ampliação não apenas do conteúdo jurídico e moral da idéia de igualdade, mas das próprias possibilidades jurídicas de concretizá-las. Assim, as políticas de ação afirmativa ancoram-se em uma crítica ao princípio de igualdade formal perante a lei e organizam-se em torno de uma demanda concreta de igualdade - a igualdade de oportunidade. ${ }^{32}$
\end{abstract}

Em 21 de março de 2003 o Governo Federal criou a Secretaria Especial de Políticas de Promoção da Igualdade Racial (Seppir), conferindo-Ihe o status de Ministério. A Seppir tem a função de articular, formular e coordenar políticas públicas em âmbito nacional para promover a igualdade racial no Brasil. Em 20 de novembro do mesmo ano foi lançada a Política Nacional de Promoção da Igualdade Racial, que traça as diretrizes para a indicação de programas e ações do Governo Federal para a redução das desigualdades raciais no Brasil.

De acordo com SANTOS, '[...] uma política de igualdade centrada na redistribuição social da riqueza não pode ser conduzida com sucesso sem uma política de reconhecimento da diferença racial, étnica, cultural ou sexual, e viceversa". ${ }^{33} \mathrm{E}$ isso implica em conhecer a situação de desigualdade com que convivem os diferentes grupos sociais em nosso país. Buscar alternativas, principalmente através de políticas públicas, com ações em conjunto entre entidades governamentais, não-governamentais e sociedade civil para que haja uma mudança efetiva frente às questões que norteiam a discriminação racial, para tão-somente buscar-se a promoção da igualdade racial na sociedade brasileira.

\title{
CONCLUSÕES
}

As políticas públicas de ação afirmativa são iniciativas de ordem governamental e não governamental com a finalidade de adotar medidas que visem à equidade de tratamento entre pessoas que ocupam posições desiguais. Essas ações promovem um tratamento diferenciado a certos grupos, que estejam em desvantagem de condições e oportunidades socais em relação a outros grupos. Prevêem, portanto que seja alcançado o equilíbrio das relações sociais entre os diversos grupos da sociedade, colocando-os em mesmo patamar de igualdade e de oportunidades. 
As ações afirmativas voltadas para a população negra têm a finalidade de promover a igualdade racial entre os diversos grupos sociais. Além de representarem uma ferramenta importante para o combate ao preconceito racial, ao racismo e a discriminação racial, pois essas medidas têm a finalidade de inserir os grupos sociais negros nos diversos setores sociais. Não há que se falar em convivência harmoniosa entre os diferentes grupos sociais, conforme a falsa democracia racial atestada por alguns autores no início do século $X X$, pois os grupos raciais não tem uma convivência harmoniosa. É imprescindível a implementação das ações afirmativas como alternativa para equilibrar as relações raciais no país e assegurar os direitos fundamentais inerentes a população negra.

É no reconhecimento de uma sociedade pluralista que o direito atual se obriga a normatizar as relações sociais, não mais com a velha concepção de seguir cegamente a norma genérica e abstrata para todos os conflitos, mas com uma nova forma de encará-los na sua singularidade. Devemos pensar o direito como instrumental de luta e mobilização social para a melhora na condição de vida de muitos brasileiros, mesmo que para isso tenhamos que buscar alternativas que não aquelas editadas pelas regras jurídicas.

Diante da realidade brasileira em que é evidenciado as profundas desigualdades sociais e raciais entre os diversos grupos que compõe nossa sociedade '[...] adquire-se a certeza de que devem ser tomadas medidas voltadas para sua reversão. Essas medidas, chamadas ações afirmativas, cada vez mais aparecem no debate político e intelectual brasileiro [... $]^{334}$ como alternativa de reverter essa situação e promover um equilíbrio social entre os grupos. Em relação à população negra, as ações afirmativas vão mais além, pois têm como principal função promover a igualdade racial e a valorização da diversidade étnico-racial.

\section{POLICIES FOR AFFIRMATIVE ACTION TO DELIVER THE RIGHTS OF BLACK SOCIAL GROUPS IN BRAZIL}

\section{ABSTRACT}

This study underscores the importance of investing in affirmative action policies to achieve the rights of black social groups in the country and to promote racial equality in society. In this sense, the aim was to highlight the social and historical construction of race relations in Brazil and the consequences of affirmative action policies in the realization of citizenship rights of minorities.

Keywords: Affirmative action. Black minority. Racial equality.

\footnotetext{
Doutora em Direito pela Universidade Federal de Santa Catarina. Professora da Graduação e Pós-Graduação Lato Sensu da FACINTER e do CESUMAR. Professora do Programa de Mestrado em Direito do CESUMAR. Pesquisadora do CNPq e Bolsista Produtividade em Pesquisa da FUNADESP. E-mail: annoni@justice.com
} 
2 Mestranda no Curso de Pós-Graduação em Direito da Universidade Federal de Santa Catarina (CPGD/UFSC), Graduada em Direito (UNESC). Pesquisadora do Núcleo de Estudos Jurídicos e Sociais da Criança e do Adolescente (NEJUSCA/UFSC) e do Núcleo de Estudos em Estado, Política e Direito (NUPED/UNESC). E-mail: fernanda lima55@hotmail.com

3 De acordo com GOMES o racismo resulta de uma ação "por vezes do ódio, em relação a pessoas que possuem um pertencimento racial obsenvável por meio de sinais, tais como: cor da pele, tipo de cabelo, etc." O racismo está no imaginário do ser humano racista que acredita haver a existência de seres humanos superiores e inferiores. Já o preconceito é '[...] um julgamento negativo e prévio dos membros de grupo racial de pertença, de uma etnia ou de uma religião ou de pessoas que ocupam outro papel significativo". Ressalta a autora que esse julgamento prévio, que pode não se materializar em ações, pois está no campo da consciência humana, têm o caráter da inflexibilidade, pois tende a ser mantido sem levar em consideração os fatos que o contestem. Já a discriminação racial é a manifestação direta ou indireta dessas imagens construídas pelo racismo e pelo preconceito racial. GOMES, Nilma Lino. Alguns termos e conceitos presentes no debate sobre relações raciais no Brasil: uma breve discussão. In Secretaria de Educação Continuada, Alfabetização e Diversidade. Educação anti-racista: caminhos abertos pela Lei Federal $n^{\circ}$ 10.639/03. Col. Educação para todos. Brasília: Ministério da Educação, SECAD, 2005, p. 52.

4 BRASIL, Secretaria Especial de Políticas de Promoção da Igualdade Racial. Estado e sociedade promovendo a igualdade racial. Relatório, 2005, p. 12.

5 FERNANDES, Florestan. O negro no mundo dos brancos. Apresentação de Lilia Moritz Schwarcz. 2. ed. revista. São Paulo: Global, 2007, p. 33.

6 BRASIL, Secretaria Especial de Políticas de Promoção da Igualdade Racial. Estado e sociedade promovendo a igualdade racial. Op. cit., 2005, p. 12.

7 FREYRE, Gilberto. Casa Grande e Senzala. CASA-GRANDE \& senzala: formação da família brasileira sob o regime de economia patriarcal. Rio de Janeiro: Maia \& Schmidt, 1933.

Sobrados e mocambos: decadência do patriarcado rural e desenvolvimento do urbano. São Paulo: Companhia Editora Nacional, 1936. . INTERPRETAÇÃO do Brasil: aspectos da formação social brasileira como processo de amalgamento de raças e culturas. Traduzido por Olívio Montenegro. Rio de Janeiro: José Olympio, 1947. (Documentos Brasileiros, 56)

8 CHAUI, Marilena. Brasil: mito fundador e sociedade autoritária. São Paulo: Editora Fundação Perceu Abramo, 2000, p. 26.

9 GUIMARÃES, Antônio Sergio Alfredo. Preconceito Racial: modos, temas e tempos. Col. Preconceitos, v. 6. São Paulo: Cortez, 2008, p. 55.

10 A Frente Negra Brasileira, transformada em partido político no ano de 1936, foi dissolvida no ano seguinte, assim como os demais partidos políticos pelo Governo Vargas, período reconhecido historicamente como Estado Novo. Cf. LMA, Ivan Costa. Pedagogia interétnica: uma proposta do movimento negro em Salvador (1974-1990). In.: OLIVEIRA, Iolanda de. SILVA, Petronilha Beatriz Gonçalves e. PINTO, Regina Phaim (orgs). Negro e educação: escola, identidades, cultura e políticas públicas. São Paulo: Ação Educativa, ANPEd, 2005, p. 41.

Idem, ibidem.

12 GUIMARÃES, Antônio Sergio Alfredo. Preconceito Racial. Op. cit,, p. 62.

13 LIMA, Ivan Costa. Pedagogia interétnica. Op. cit, p. 42.

14 FERNANDES, Florestan. O negro no mundo dos brancos. Op. cit., 2007.

15 Paulo Bonavides enfatiza que "As comoções políticas de raiz social fizeram-na desembocar, por obra da corrupção do regime presidencial, na segunda ditadura do século, a mais longa e perniciosa por haver mantido aberto um Congresso fantoche, debaixo de uma Constituição de fachada outorgada pelo sistema autoritário, que ao mesmo tempo censurava a imprensa e reprimia a formação, pelo debate livre, de novas lideranças, sacrificando assim toda uma geração. Tal aconteceu em 1964 quando o país atravessou durante duas décadas a mais sombria ditadura militar de sua história". Cf.: BONAVIDES, Paulo. A evolução Constitucional do Brasil. Estudos Avançados. 14 (40), Scielo. 2000, p. 174.

17 O termo "negro" utilizado para quantificar a população brasileira no censo do IBGE de 2000 refere-se a população parda e preta, classificação esta utilizada pelo instituto de pesquisa. 
Idem, ibidem.

IBGE. Síntese dos Indicadores Sociais 2007. Op. cit. p. 211.

Idem, p. 41.

GUIMARÃES, Antônio Sérgio Alfredo. Racismo e Anti-racismo no Brasil. 2. ed. São Paulo: Editora 34, 1999, p. 169-170.

24 SOUZA, Paulo Antônio de. As ações afirmativas perante a Constituição Federal. A questão do fator racial. Dissertação (Mestrado em Direito). Programa de Pós-Graduação em Direito Internacional Econômico da Universidade Católica de Brasília, Brasília, 2006, p. 32-33.

ALMEIDA, Mônica Andréia Oliveira. Políticas de ação afirmativa e ensino superior: a experiência do curso de Serviço Social da PUC-RIO. Dissertação (Mestrado em Educação). Programa de Pós-Graduação em Educação do Departamento de Educação do Centro de Teologia e Ciências Humanas da PUC-RIO. Rio de Janeiro, 2003, p. 31.

Idem., p. 32.

27 CARDOSO, Fernando Henrique. Pronunciamento do Presidente da República. Abertura do Seminário Multiculturalismo e Racismo: o papel da Ação Afimativa nos Estados Democráticos Contemporâneos. Brasília: Ministério da Justiça, 1996, p. 14-15.

GOMES, Joaquim Barbosa. $O$ debate constitucional sobre as ações afirmativas. In: SANTOS, Renato Emerson dos. LOBATO, Fátima. Ações afirmativas. políticas públicas contra as desigualdades raciais. (orgs) Rio de Janeiro: DP\&A, 2003, p. 21.

VIEIRA, Andréa Lopes da Costa. Políticas de educação, educação como política: observações sobre a ação afirmativa como estratégia política. In: SILVA, Petronilha Beatriz Gonçalves e. SILVÉRIO, Valter Roberto. Educação e Açôes Afirmativas: entre a injustiça simbólica e a injustiça econômica. Brasília: Instituto Nacional de Estudos e Pesquisas Educacionais Anísio Teixeira, 2003 , p. 87.

31 JACCOUD, Luciana de Barros; BEGHIN, Nathalie. Desigualdades Raciais no Brasil: um balanço da intervenção governamental. Brasília: Ipea, 2002, p. 47.

32 Idem, p. 45.

33 SANTOS, Boaventura de Sousa. Gramática do tempo: para uma nova cultura política. Col. Para um nov senso comum. , v. 4. São Paulo: Cortez, 2006, p. 194.

34 VIEIRA, Andréa Lopes da Costa. Politicas de educação, educação como politica. Op. cit., p. 86.

\section{REFERÊNCIAS}

ALMEIDA, Mônica Andréia Oliveira. Políticas de ação afirmativa e ensino superior: a experiência do curso de Serviço Social da PUC-RIO. Dissertação (Mestrado em Educação). Programa de Pós-Graduação em Educação do Departamento de Educação do Centro de Teologia e Ciências Humanas da PUC-RIO. Rio de Janeiro, 2003.

BONAVIDES, Paulo. A evolução Constitucional do Brasil. Estudos Avançados. 14 (40), Scielo: 2000.

BRASIL, Secretaria Especial de Políticas de Promoção da Igualdade Racial. Estado e sociedade promovendo a igualdade racial. Relatório, 2005.

CARDOSO, Fernando Henrique. Pronunciamento do Presidente da República. Abertura do Seminário Multiculturalismo e Racismo: o papel da Ação Afirmativa nos Estados Democráticos Contemporâneos. Brasília: Ministério da Justiça, 1996.

CHAUI, Marilena. Brasil: mito fundador e sociedade autoritária. São Paulo: Editora Fundação Perceu Abramo, 2000. 
FERNANDES, Florestan. 0 negro no mundo dos brancos. Apresentação de Lilia Moritz Schwarcz. 2. ed. revista. São Paulo: Global, 2007.

GOMES, Joaquim Barbosa. O debate constitucional sobre as ações afirmativas. In: SANTOS, Renato Emerson dos. LOBATO, Fátima. Ações afirmativas. políticas públicas contra as desigualdades raciais. (orgs) Rio de Janeiro: DP\&A, 2003.

GOMES, Nilma Lino. Alguns termos e conceitos presentes no debate sobre relações raciais no Brasil: uma breve discussão. In. Secretaria de Educação Continuada, Alfabetização e Diversidade. Educação anti-racista: caminhos abertos pela Lei Federal $n^{0}$ 10.639/03. Col. Educação para todos. Brasília: Ministério da Educação, SECAD, 2005.

GUIMARÃES, Antônio Sérgio Alfredo. Racismo e Anti-racismo no Brasil. 2. ed. São Paulo: Editora 34, 1999.

GUIMARÃES, Antônio Sérgio Alfredo. Classes, Raça e Democracia. São Paulo: Editora 34, 2002.

GUIMARÃES, Antônio Sergio Alfredo. Preconceito Racial. modos, temas e tempos. Col. Preconceitos, v. 6. São Paulo: Cortez, 2008.

IBGE. Censo Demográfico 2000: Dados da amostra. Rio de Janeiro: IBGE. Disponível em: <http://www.ibge.gov.br>. Acesso em: 12 de abril de 2009.

IBGE. Síntese dos Indicadores Sociais 2007. Rio de Janeiro: IBGE, 2008.

JACCOUD, Luciana de Barros; BEGHIN, Nathalie. Desigualdades Raciais no Brasit. um balanço da intervenção governamental. Brasília: Ipea, 2002.

LIMA, Ivan Costa. Pedagogia interétnica: uma proposta do movimento negro em Salvador (1974-1990). In: OLIVEIRA, Iolanda de. SILVA, Petronilha Beatriz Gonçalves e. PINTO, Regina Phaim (orgs). Negro e educação: escola, identidades, cultura e políticas públicas. São Paulo: Ação Educativa, ANPEd, 2005.

SANTOS, Boaventura de Sousa. Gramática do tempo: para uma nova cultura política. Col. Para um nov senso comum. , v. 4. São Paulo: Cortez, 2006.

SOUZA, Paulo Antônio de. As ações afirmativas perante a Constituição Federal. A questão do fator racial. Dissertação (Mestrado em Direito). Programa de PósGraduação em Direito Internacional Econômico da Universidade Católica de Brasília, Brasília, 2006.

VIEIRA, Andréa Lopes da Costa. Políticas de educação, educação como política: observações sobre a ação afirmativa como estratégia política. In: SILVA, Petronilha Beatriz Gonçalves e. SILVÉRIO, Valter Roberto. Educação e Ações Afirmativas. entre a injustiça simbólica e a injustiça econômica. Brasília: Instituto Nacional de Estudos e Pesquisas Educacionais Anísio Teixeira, 2003. 
Recebido para publicação 27/10/2009

Aceito para publicação 19/12/2009 